\title{
Role of service quality, trust and loyalty in building patient-based brand equity: Modeling for public hospitals
}

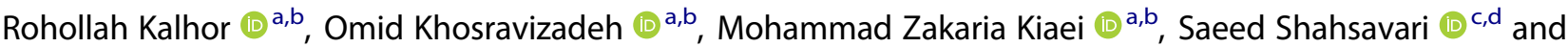 \\ Mohammad Badrlo (10 ${ }^{\mathrm{e}}$ \\ aSocial Determinants of Health Research Center, Research Institute for Prevention of Non-Communicable Diseases, Qazvin University of

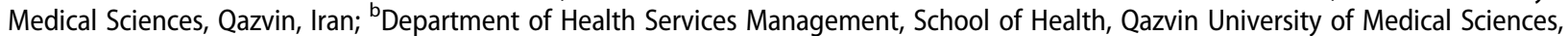 \\ Qazvin, Iran; 'Department of Epidemiology and biostatistics, School of Public Health, Tehran University of Medical Sciences, Tehran, Iran;

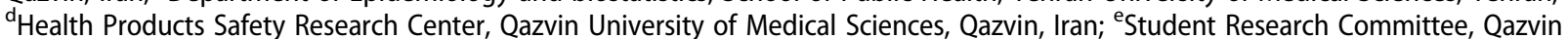 \\ University of Medical Sciences, Qazvin, Iran
}

\begin{abstract}
In the current competitive situation, hospitals are seeking to keep their position among patients. This study aimed to find factors influencing on the brand equity of hospitals.in the cross sectional study, Firstly, the factors affecting the brand equity were identified Subsequently, by holding the panel of experts, the effective factors were taken into account After standardization, the questionnaire was given to 450 admitted patients in Qazvin's hospitals. Finally, the causal relationship between the variables was evaluated using the Structural Equation Model (SEM) on AMOS22 software, with a significant level of 0.05. Analysis of findings revealed all fit indices were in an acceptable level. The path coefficient between brand trust and brand loyalty with brand equity was positive $(t>1.96)$. Study result is necessary for hospitals to prioritize attention to dimensions and factors affecting brand equity in order to maintain their place in society and provide effective services
\end{abstract}

\section{ARTICLE HISTORY}

Received 9 July 2019 Accepted 2 April 2020

\section{KEYWORDS}

Patients; brand equity hospital; structural Equation modeling; service quality

\section{Introduction and background}

Nowadays, marketing is one of the basic needs of each organization for survival, and to enhance the products quality and offered services. The lack of attention to marketing in non-commercial organizations such as healthcare will lead to waste of resources, and impose social and economic costs. In this regard, one of the most important marketing concepts widely discussed by marketing experts is brand equity, which plays a strategic and significant role in management decisions and creates competitive advantages for organizations and their customers [1,2]. Healthcare centers encounter special challenges around the world. An extended number of healthcare centers face really competitive conditions owing to open-door policies in medical service markets [3]. In this regard, creation of a renowned hospital brand would be a valuable tool for managers to hire and keep doctors and nurses [4]. Having a strong brand in the market is one of the fundamental goals of most organizations. Financial experts believe that a commercial brand can provide more than just a common value. Today, a brand not only is an effective tool among managers, but also is a strategic requirement which helps organizations in the creation of value for customers. It also assists in the creation of sustainable competitive advantages. Successful brands contribute to an increase in customers' trust to intangible products and services enabling them in better identification of their needs. Moreover, a high level of brand equity enhances customers' satisfaction, their rebate and also loyalty levels [5], which is beside a key role the brand plays in business success [6,7]. There are a lot of different studies which have highlighted the importance of brand equity, especially in healthcare organizations and have regarded it as a significant change to maintain market share. In such investigations, various variables were considered with respect to their context and purpose. In this regard, it could be referred to several studies on military hospitals of Iran [8], Yazd hospitals, Iran [9], Seoul hospitals, Korea [10], Indonesia. Hospitals [11], and also some systematic and comprehensive research in Iran and all around the world as examples. In the current situation, hospitals are seeking to obtain more market share and preserve it. They have also been making an effort to discover new ways to generate more value in their customers' mind. However, what is problem is that the managers have no information about factors contribute to their brand equity creation in the mind of patients and customers, and the way they have to manage the brand' effectiveness [12]. Hence, the objective of this study was to design a questionnaire, to identify effective dimensions on the brand equity of medical centers, and to determine their relationship in a model framework. 